\title{
Osteomyelitis and osteonecrosis in inflammatory bowel disease
}

\author{
Hugh J Freeman MD
}

HJ Freeman. Osteomyelitis and osteonecrosis in inflammatory bowel disease. Can J Gastroenterol 1997;11(7):601-606. Osteomyelitis and osteonecrosis are skeletal disorders seen in patients with inflammatory bowel disease (IBD). Osteomyelitis usually occurs in the pelvic bones, especially in complicated Crohn's disease, presumably by direct extension from a pelvic inflammatory mass, abscess or fistulous tract. Diagnosis of osteomyelitis may be difficult and can lead to spinal extension of the septic process with a resultant neurological deficit, including paraplegia. Osteonecrosis or avascular necrosis has been reported in patients with either ulcerative colitis or Crohn's disease, often, but not exclusively, during or following steroid treatment. The disease is often multifocal, but its natural history is unknown, especially if diagnosed early with modern imaging methods, such as magnetic resonance. In IBD patients, the relationship between osteonecrosis and steroid use is unknown. An adverse steroid effect on bones, especially the femoral heads, may develop in some patients with IBD but, to date, this hypothesis remains unproven. Critical evaluation of published data reveals no consistent association between osteonecrosis and steroid treatment in IBD patients.

Key Words: Arthritis, Avascular necrosis, Bone abscess, Bone disease, Crohn's disease, Granulomatous ulcerative colitis

\section{Ostéomyélite et ostéonécrose dans la maladie inflammatoire de l'intestin}

RÉSUMÉ : L'ostéomyélite et l'ostéonécrose sont des troubles du squelette que l'on observe chez les patients atteints de maladie inflammatoire de l'intestin (MII). L'ostéomyélite survient habituellement au niveau des os du bassin, surtout dans la maladie de Crohn compliquée et résulte probablement d'une extension directe d'une masse, d'un abcès ou d'une fistule inflammatoire au niveau du bassin. Le diagnostic de l'ostéomyélite peut être difficile à poser et peut s'étendre vers la colonne vertébrale avec le déficit neurologique qui s'ensuit, y compris la paraplégie. L'ostéonécrose ou la nécrose avasculaire a été signalée chez les patients qui souffrent soit de colite ulcéreuse soit de maladie de Crohn, souvent, mais non exclusivement durant la corticothérapie. La maladie est souvent multifocale, mais son histoire naturelle est inconnue, surtout si elle est diagnostiquée tôt au moyen de méthodes d'imagerie moderne comme l'imagerie par résonance magnétique. Chez les patients atteints de MII, le lien entre ostéonécrose et corticothérapie reste inconnu. L'effet indésirable de la corticothérapie sur les os, surtout au niveau des têtes fémorales peut s'installer chez certains patients et à ce jour, l'hypothèse n'a pu être prouvée. L'évaluation critique des données publiées ne révèle aucune association concluante entre l'ostéonécrose et la corticothérapie chez les patients atteints de MII.
A bout $25 \%$ of patients with inflammatory bowel disease (IBD) will develop a rheumatological complication, many of which directly involve bone (1-3). Some common disorders seen in Crohn's disease or ulcerative colitis include central or axial arthropathies, ankylosing spondylitis and sacroiliitis, as well as peripheral (or 'enteropathic') arthropathies. These disorders primarily involve joint spaces, synovia and soft tissues; only later, or secondarily, are bone changes seen, such as joint space erosions, sclerosis, narrow- ing and ligamentous ossification. In some patients, increased joint disease activity is related to an exacerbation of the underlying intestinal disorder; in others, there is no evident link to intestinal disease activity, and the disorders appear completely independent.

In some, but not all, patients with IBD and ankylosing spondylitis, human leukocyte antigen B27 has been observed $(1,2)$. In addition, subclinical inflammatory changes in the intestine have been observed in over half of patients with

Department of Medicine (Gastroenterology), University of British Columbia, Vancouver, British Columbia

Correspondence and reprints: Dr HJ Freeman, ACU F-137, Gastroenterology, Vancouver Hospital (UBC Site), 2211 Wesbrook Mall, Vancouver, British Columbia V6T 1W5. Telephone 604-822-7216, fax 604-822-7236

Received for publication December 18, 1996. Accepted March 18, 1997 
spondyloarthropathy (4-9), with evolution to frank IBD in about $7 \%$ (10). Finally, a transgenic mouse model of human IBD with arthropathy has been reported to be relevant to future immunopathogenesis studies $(11,12)$.

Metabolic bone diseases, including osteoporosis, develop in an estimated $30 \%$ of IBD patients (13-16). In these patients, osteopenic bone disease is probably multifactorial. Anorexia may result in impaired intake of calcium and vitamin D. Associated hepatic or biliary tract disease may cause impaired conversion of vitamin D to its active metabolites. Reduced mucosal surface area due to small intestinal disease or repeated intestinal resections may result in impaired absorption and malnutrition. Although steroid therapy may contribute to bone loss, IBD patients may initially present with low bone mass before commencement of steroid therapy (17). There is a poor correlation between bone mass and steroid intake $(15,18-20)$. Recent studies in a rat model of colitis indicate that bone loss may also be attributable to the inflammatory process (21). Bone formation and modelling may be suppressed, possibly due to systemic factors, such as the inflammatory cytokines (ie, interleukin-1 and tumour necrosis factor-alpha). These inhibit bone formation by suppressing osteoblast proliferation (22-24) and enhancing bone resorption (25-27).

Other very distinctive, but rarely reported, skeletal disorders can occur in patients with IBD. These include osteomyelitis and osteonecrosis (or avascular necrosis of bone). Both cause significant morbidity and must be differentiated from the musculoskeletal disorders described above and other rare entities, including periosteal new bone formation (28-30) and granulomatous bone disease $(31,32)$. Osteonecrosis has recently assumed significance related to litigation based on the misconception that osteonecrosis is caused by corticosteroids in IBD patients. As a result, use of highly effective and inexpensive corticosteroid medications, such as prednisone, to treat IBD may be curtailed in favour of earlier 'curative' surgical treatment, including ablative procedures with pelvic pouch reconstruction, that can also cause morbidity and mortality. Moreover, pharmaceutical companies have focused much of their marketing efforts, including some multicentre studies on budesonide therapy for Crohn's disease in Canada $(33,34)$, on 'safe' but expensive corticosteroids for IBD (35). These recent studies, however, lack specific data on the effects of these agents on skeletal metabolism. In a recent report (36), however, four cases of aseptic bone necrosis were noted during budesonide controlled ileal release therapy.

This review examines osteomyelitis and osteonecrosis in IBD, complications that result from these two skeletal disorders, and published data on osteonecrosis and steroid use, particularly in ulcerative colitis and Crohn's disease.

\section{OSTEOMYELITIS}

While many inflammatory intestinal tract disorders occur adjacent or very close to the bony pelvic structures, osteomyelitis involving the pelvic bones is rare. In over $600 \mathrm{pa}-$ tients with osteomyelitis, only $5 \%$ had involvement of the bony pelvis (37). Usually the infection is spread by contiguous extension from a soft tissue focus or, less commonly, from an intra-abdominal or intrapelvic abscess. The resulting osteomyelitis is usually located in the bony ilium, probably because it is the largest of the pelvic bones with a large blood supply.

The precise frequency of osteomyelitis in IBD is unknown but the first cases were described in Crohn's disease by Goldstein et al in 1969 (38), London and Fitton in 1970 (39) and Meltzer in 1973 (40). Since then, only a few other cases have been reported in IBD patients (41-53). This seems surprising because of the frequent presence of an associated pelvic inflammatory mass, abscess or fistulous tract in Crohn's disease. Osteomyelitis in ulcerative colitis is even more rare (54).

Most cases of osteomyelitis involve the bony structures on the right side of the pelvis, specifically the bony right ilium. Undoubtedly, the location is related to the nearby or adjacent terminal ileum and cecum, especially common sites of clinically defined involvement in Crohn's disease. In most patients with Crohn's disease and osteomyelitis, a localized abscess or fistula is also present, suggesting that infection resulted from seeding to contiguous bone. Exceptions, however, do occur. In one report (42), for example, osteomyelitis of the femur was seen in Crohn's disease complicated by an Escherichia coli septicemia. The patient had received corticosteroids and immunosuppressive medications.

With sacral osteomyelitis in Crohn's disease, presacral and perirectal abscesses are usually present. In most of those patients, the diagnosis of Crohn's disease was made before diagnosis of osteomyelitis, which is not surprising because osteomyelitis usually occurs exclusively in patients with Crohn's disease complicated by sepsis. In contrast, Schwartz et al (44) detailed a case of sacral osteomyelitis as the presenting clinical manifestation in Crohn's disease that was detected only at laparotomy despite extensive preoperative radiographic studies.

The significant clinical feature in each aforementioned case of osteomyelitis was severe and persistent pain in the affected area. This can be overlooked in a patient chronically ill with other complications of Crohn's disease. Moreover, diagnosis may be difficult if pain is present in the abdomen, pelvis or affected area because it might be attributed to either an abscess or fistula. In addition, diagnosis may be elusive in some patients with sacroiliitis and/or spondylitis complicating IBD because either of these can result in disabling and severe back pain.

Diagnosis may be difficult, even if occult osteomyelitis is suspected. The typical radiographic osseous changes of osteomyelitis may not appear for days or even weeks. Isotopic bone scans may offer sensitivity approaching $100 \%$, and other imaging modalities, including computerized tomography $(\mathrm{CT})$, may be helpful to detect sequestra and altered anatomy (45). In a study of 80 consecutive patients with symptomatic Crohn's disease referred for CT imaging, two had unsuspected sacral osteomyelitis (46). Magnetic resonance imaging (MRI) may also be extremely useful. It is 
more precise than other imaging modalities for definition of extent of an inflammatory process and differentiation of osteomyelitis from cellulitis (48).

Pelvic sepsis may be further complicated by extension of the septic or inflammatory process into the spinal canal causing transient or even permanent neurological complications - particularly if concomitant sacral osteomyelitis is documented. There are now several descriptions in the English literature of Crohn's disease with fistula formation extending into the spinal canal causing serious sequelae, such as a spinal epidural abscess. Aitken et al (49), for example, first described an epidural abscess in a 36-year-old male with Crohn's disease of the terminal ileum and a pelvic inflammatory mass resulting in paraplegia. In addition, Sacher and co-workers (50) reported an 11-year-old male with Crohn's disease of the colon and a right psoas abscess complicated by a spinal epidural abscess from L2 to S4. Finally, Hershkowitz et al (51) described a 19-year-old male with epidural and subdural empyema originating from a rectal fistula.

The precise pathogen in osteomyelitis may be difficult to define because the clinical course of osteomyelitis often necessitates antibiotic use to treat other septic complications. Often, the organisms involved in pelvic osteomyelitis originate from bowel flora, but, unfortunately, cultures obtained from draining sinuses, adjacent abscesses or infected cavities may be misleading. A bone biopsy may best document the specific bacterial agent involved with osteomyelitis. In a comprehensive review of osteomyelitis, the frequency of positive cultures in relation to the sources of specimens was $60 \%$ for bone aspirates and $65 \%$ for bone pus obtained at the time of surgical treatment (52).

Finally, in a recent review, osteomyelitis was almost an exclusive septic complication of Crohn's disease (53). In one report (54), however, a 16-year-old female with brucellosis and ulcerative colitis was described with multiple abscesses and osteomyelitis; the presence of multifocal osteomyelitis suggested hematogenous seeding of bone rather than direct extension from an abdominal source.

In summary, osteomyelitis is a serious but fortunately rare skeletal complication of IBD, particularly complicated Crohn's disease. In addition to difficulties in diagnosis and management, however, there is a need to be alert for the insidious development of serious clinical sequelae of osteomyelitis, including transient or permanent neurological complications due to extension of the pelvic or bony septic process into the spinal canal.

\section{OSTEONECROSIS (AVASCULAR NECROSIS)}

Osteonecrosis, or nontraumatic (aseptic, avascular) bone necrosis, is estimated to account for over $10 \%$ of joint replacements (55). Although several clinical entities have been associated with osteonecrosis, as summarized in Table 1 , the incidence and pathogenesis of each condition is not well defined. Osteonecrosis has rarely been reported in patients with IBD, either during or after corticosteroid treatment (56-61) (Table 2). In addition, other treatments for IBD have been implicated in the pathogenesis of osteone-
TABLE 1

Causes of osteonecrosis in adults

\begin{tabular}{l} 
Idiopathic \\
Congenital \\
Legg-Calve-Perthes disease \\
Hemoglobinopathy (sickle cell crisis) \\
Infectious/inflammatory \\
Septic osteonecrosis \\
Pancreatitis \\
Traumatic osteonecrosis \\
Mechanical vascular disruption \\
Fat embolism syndrome \\
Coagulopathy \\
Toxic or drug-associated causes \\
Alcohol abuse \\
Corticosteroids \\
Endocrine/metabolic causes \\
Gout \\
Cushing's syndrome \\
Neoplastic causes, including lymphoma \\
Vascular causes \\
Connective tissue disorders (rheumatoid arthritis, systemic \\
Others, including dysbarism \\
\hline
\end{tabular}

TABLE 2

Osteonecrosis in inflammatory bowel disease (IBD)

\begin{tabular}{|c|c|c|c|c|}
\hline $\begin{array}{l}\text { Patient age } \\
\text { (years)/sex }\end{array}$ & $\begin{array}{l}\text { IBD } \\
\text { type }\end{array}$ & $\begin{array}{c}\text { Osteonecrosis } \\
\text { location }\end{array}$ & Steroids & Reference \\
\hline 27/female & $C D$ & L/R humerus & Yes & 56 \\
\hline 16/female & $C D$ & $\begin{array}{l}\text { L/R humerus, } \\
L \text { femur, } L \text { talus }\end{array}$ & Yes & 57 \\
\hline 14/female & $C D$ & L/R femur & Yes & 57 \\
\hline $16 /$ male & $C D$ & L/R femur & Yes & 57 \\
\hline 29/male & UC & $\mathrm{L} / \mathrm{R}$ femur, $\mathrm{R}$ talus & Yes & 58 \\
\hline $30 /$ male & $C D$ & $\begin{array}{l}\text { L/R femur, } \\
R \text { humerus }\end{array}$ & Yes & 58 \\
\hline 26/female & UC & L/R femur & Yes & 58 \\
\hline 29/female & UC & $\mathrm{R}$ femur & Yes & 58 \\
\hline $22 /$ male & $C D$ & L/R femur & Yes & 58 \\
\hline $27 /$ male & UC & $\mathrm{R}$ femur & Yes & 58 \\
\hline $36 /$ male & UC & L/R femur & Yes & 58 \\
\hline $46 /$ male & $C D$ & $\begin{array}{l}\text { L/R femur, } \\
\mathrm{R} \text { lunate }\end{array}$ & Yes & 59 \\
\hline 21 male & UC & L/R femur & Yes & 60 \\
\hline $38 /$ male & $C D$ & L/R femur & No & 61 \\
\hline $23 /$ male & $C D$ & L/R femur & No & 61 \\
\hline
\end{tabular}

$C D$ Crohn's disease; $L$ left; $R$ Right; UC Ulcerative colitis 
crosis, including parenteral nutrition, particularly with lipid emulsions (57). Moreover, some IBD patients may have another cause of osteonecrosis, including another disease, trauma or chronic alcoholism. Finally, patients with IBD and no prior history of corticosteroid use have developed osteonecrosis (61).

There are six published reports of osteonecrosis in patients with IBD (56-61). In 1971, Brom et al (56) described a 27-year-old female with Crohn's disease, periostitis, arthritis and aseptic necrosis of both humeral heads. Although the patient was treated with intravenous and oral corticosteroids, it was thought that the bone changes were due to Crohn's disease. Shapiro and colleagues (57) described two females, aged 14 and 16 years, and one 16-year-old male with Crohn's ileocolitis and multifocal osteonecrosis. All patients received corticosteroids as well as parenteral nutrition with infused lipids for four to six weeks. After remission, steroids were gradually discontinued. Because congenital hyperlipidemia in rabbits (62) and hyperlipidemia in humans (63) have been seen with osteonecrosis, it was hypothesized that the combination of lipid infusion and steroids might be additive in children with Crohn's disease, because both factors can increase serum lipid levels, causing fat embolism and altered diffusion of oxygen to metabolically active bone tissue, and, ultimately, bone ischemia and necrosis (63).

Vakil and Sparberg (58) described seven patients with osteonecrosis (five with ulcerative colitis and two with Crohn's disease) in a group of 161 IBD patients treated with steroids. Osteonecrosis developed in the seven patients within six months after initiation of steroid therapy. It was suggested that IBD may predispose patients to steroidassociated osteonecrosis. This result was consistent with the findings of Cruess (64), who reported that steroid-associated osteonecrosis occurred within six to eight months of therapy initiation, whereas osteopenic complications occurred two to three years later. In contrast, Culp et al (59) reported lunate and femoral head osteonecrosis in a 46-year-old male with Crohn's disease two years after a one-month course of $7.5 \mathrm{mg} /$ day prednisone. In addition, Madsen and Andersen (60) described a 21-year-old male with ulcerative colitis and multifocal osteonecrosis after steroid treatment; MRI was used for diagnosis. The authors argued that early diagnosis might make earlier treatment possible so that collapse of subchondral bone and progression of the disease may be averted. Finally, in a report published in 1993 (61), two males, aged 38 and 23 years, with Crohn's disease and no history of prior corticosteroid treatment were diagnosed with osteonecrosis, suggesting that osteonecrosis might be a disease complication rather than be due to IBD treatment.

In summary, osteonecrosis is a disorder of unknown pathogenesis that has been reported (55) to complicate several clinical disorders, including IBD (61). Usually, one or both femoral heads are involved, but any bone may be affected, and frequently it is a multifocal process. Clinical diagnosis is difficult, and the natural history of osteonecrosis is unknown. If changes are radiologically defined, the process is not likely to be reversible. Surgical decompressive proce- dures have been used but their role is unclear, especially if detected with MRI. Patients with radiologically defined bone necrosis and collapse will likely require joint replacement to maintain function and mobility.

\section{CORTICOSTEROIDS AND OSTEONECROSIS}

The critical elements in the pathogenesis of osteonecrosis are unknown. However, a possible association with corticosteroids was first described in 1957 (65), followed by English language reports (66-69). Later, a more definite association was described following renal transplantation, with a recorded prevalence of up to $20 \%(70,71)$, and in patients with systemic lupus erythematosus (prevalence of up to $40 \%$ ) (72-75). Although osteonecrosis was seen in other conditions treated with corticosteroids, its prevalence was so low that a strong statistical relationship could not be defined, except possibly in patients with malignant lymphoma (76-79). Although corticosteroids alone have not been shown to cause osteonecrosis in animals (80), other criteria need to be considered before suggesting that an adverse pharmacological event has occurred in IBD.

For example, a consistent association between corticosteroids and osteonecrosis in patients with IBD is still needed. The published literature to date is contradictory. Of the six reports (56-61) on osteonecrosis in IBD, all are either single cases or series of cases, with three (57), seven (58) or two (61) patients. In the first series (57), the authors noted that, in their experience, osteonecrosis was not seen in children with IBD who were receiving corticosteroid doses without intravenous lipids. In the second series (58), seven patients with either ulcerative colitis or Crohn's disease were described but modes of treatment other than corticosteroids, including parenteral lipid infusions, were not detailed. An estimated $4.3 \%$ of IBD patients seen in those authors' tertiary centre developed radiologically defined osteonecrosis; whether patients with already established osteonecrosis were included was not clear. It was suggested, however, that IBD may predispose patients to osteonecrosis. In a final report (61), osteonecrosis occurred in two patients with no prior corticosteroid use.

Definition of a specific dose-response gradient, to include the total cumulative dose, the highest dose or the duration of drug treatment, is crucial. In disorders treated with high doses of corticosteroids (eg, renal transplant recipients), there is some evidence for a dose-response gradient. In contrast, for disorders (such as rheumatoid arthritis) treated with low steroid doses even for prolonged periods, osteonecrosis is rare. Moreover, there are reports of osteonecrosis after only short term steroid treatment, especially in the neurosurgical literature $(81,82)$. In an evaluation of 22 papers on steroids in renal transplant recipients and patients with systemic lupus erythematosus (83), a relationship with total daily dose of prednisone was described (ie, $4.6 \%$ increase in osteonecrosis risk for every $10 \mathrm{mg} /$ day increase in prednisone). In contrast, a prospective study of 54 systemic lupus erythematosus patients showed that the duration of prednisone treatment, total cumulative dose and mean daily dose did not 
differ in patients with or without osteonecrosis (84). However, the mean daily prednisone dose in months of maximal treatment was more in those with osteonecrosis. Interestingly, osteonecrosis was reduced or even avoided after altering other components of the treatment regimen, except for steroid dose, in transplant recipients (85). Finally, osteonecrosis is rare in some disorders treated with high steroid doses (eg, temporal arteritis, chronic active hepatitis). To date, then, data do not support that osteonecrosis is caused by steroids, except in some diseases, specifically renal transplant recipients or patients with either systemic lupus erythematosus or, possibly, malignant lymphoma.

A consistent temporal relationship between corticosteroid treatment and osteonecrosis is not evident in IBD patients. Cruess (64) had initially suggested that osteonecrosis in some diseases occurred within six to eight months of initiation of steroids. Subsequently, Vakil and Sparberg (58) noted that osteonecrosis was only seen in their patients during or within six months of steroid treatment, even though the medication may have been initiated years earlier. In con-

ACKNOWLEDGEMENTS: The author is grateful to Dr John Ruedy, former Professor of Medicine, University of British Columbia and currently Dean of Medicine, Dalhousie University, for his guidance, inspiration and critical input that resulted in this review manuscript.

\section{REFERENCES}

1. Weiner SR, Clarke J, Taggart NA, Utsinger PD. Rheumatic manifestations of inflammatory bowel disease. Semin Arthritis Rheum 1991;20:353-66.

2. Schoor-Lesnick B, Brandt LJ. Selected rheumatologic and dermatologic manifestations of inflammatory bowel disease. Am J Gastroenterol 1987;83:216-23.

3. Levine JB. Arthropathies and ocular complications of inflammatory bowel disease. In: Targan SR, Shanahan F, eds. Inflammatory Bowel Disease. From Bench to Bedside. Baltimore: Williams and Wilkins, 1994:668-81.

4. De Vos M, Cuvelier C, Mielants H, Veys E, Barbier F, Elewaut A. Ileocolonoscopy in seronegative spondyloarthropathy. Gastroenterology 1989;96:3390-44.

5. Mielants H, Veys EM, Cuvelier C, Botelberghe L. HLA-B27 related arthritis and bowel inflammation. Part 2: Ileocolonoscopy and bowel histology in patients with HLA-B27 related arthritis. J Rheumatol 1985;12:294-8.

6. Mielants H, Veys EM, Goemaere S, Goethals K, Cuvelier C, De Vos M. Gut inflammation in the spondyloarthropathies: clinical, radiologic, biologic and genetic features in relation to the type of histology. A prospective study. J Rheumatol 1991;18:1542-51.

7. Mielants H, Veys EM, Joos R, Cuvelier C, De Vos M, Proot F. Late onset pauciarthicular juvenile chronic arthritis: relation to gut inflammation. J Rheumatol 1990;14:459-65.

8. Simenon G, Van Gossum A, Adler M, Rickaert F, Appelboom T. Macroscopic and microscopic gut lesions in seronegative spondyl-arthropathies. J Rheumatol 1990;17:1491-4.

9. Leirisalo-Repo M, Turunen U, Stenman S, Helenius P, Seppala K. High frequency of silent inflammatory bowel disease in spondyloarthropathy. Arthritis Rheum 1994;37:23-31.

10. De Vos M, Mielants H, Cuvelier C, Elewaut A, Veys E. Long-term evolution of gut inflammation in patients with spondyloarthropathy. Gastroenterology 1996;110:1696-703.

11. Hammer R, Maika S, Richardson J, Tang J, Taurog J. Spontaneous inflammatory disease in transgenic rats expressing HLA-B27 and human b2 macroglobulin. Cell 1990;63:1099-112.

12. Nickerson CL, Luthra HS, David CS. Role of enterobacteria and trast, osteonecrosis was attributed to corticosteroids in one report over two years after a course of treatment (59). Thus, no temporal relationship between steroid administration and osteonecrosis is evident in the reported IBD patients.

Finally, a biological explanation is still needed to define the clinical observations. A number of theories of causation have been proposed (56-61) but none has ever been examined in patients with IBD.

Osteonecrosis is a disorder of multiple etiologies and unknown pathogenesis that appears to be an unpredictable development in patients with IBD. Osteonecrosis seems to be associated with high doses of administered steroids in specific clinical disorders: renal transplant recipients or patients with systemic lupus erythematosus or malignant lymphoma. However, to date, evidence to define a direct relationship with corticosteroids in other disorders, including even the rare published reports in IBD patients, has been contradictory. In those with IBD, osteonecrosis has been specifically related to the disease process, rather than an adverse effect of pharmacological treatment.

HLA-B27 in spondyloarthropathies: studies with transgenic mice. Ann Rheum Dis 1990;49:426-33.

13. Genant HK, Mall JC, Wagonfeld JB, Horst JV, Lanzl LH. Skeletal demineralization and growth retardation in inflammatory bowel disease. Invest Radiol 1976;11:541-9.

14. Compston JE, Judd D, Crawley EO, et al. Osteoporosis in patients with inflammatory bowel disease. Gut 1987;28:410-5.

15. Motley RJ, Crawley EO, Evans C, Rhodes J, Compston JE. Increased rate of spinal trebecular bone loss in patients with inflammatory bowel disease. Gut 1988;29:1332-6.

16. Clements D, Motley RJ, Evans WD, et al. Longitudinal study of cortical bone loss in patients with inflammatory bowel disease. Scand J Gastroenterol 1992;27:1055-60.

17. Ghosh S, Cowen S, Hannan WJ, Ferguson A. Low bone mineral density in Crohn's disease, but not in ulcerative colitis, at diagnosis. Gastroenterology 1994;107:1031-9.

18. Bernstein CN, Seeger LL, Sayre JW, Anton PA, Artinian L, Shanahan F. Decreased bone density in inflammatory bowel disease is related to corticosteroid use and not disease diagnosis. J Bone Miner Res 1995;10:250-6.

19. Bjarnason I, Li F, Todd P, et al. Prevalence and probable cause of reduced bone density in patients with inflammatory bowel disease. J Bone Miner Res 1995;16:S111.

20. Pigot F, Roux C, Chaussade S, et al. Low bone mineral density in patients with inflammatory bowel disease. Dig Dis Sci 1992;37:1396-403.

21. Lin C-L, Moniz C, Chambers TJ, Chow JWM. Colitis causes bone loss in rats through suppression of bone formation. Gastroenterology 1996;111:1263-71.

22. Bertolini DR, Nedwin GE, Bringman TS, Smith DD, Mundy GR. Stimulation of bone resorption and inhibition of bone formation in vitro by human tumour necrosis factors. Nature 1986;319:516-8.

23. Smith DD, Gowen M, Mundy GR. Effects of interferon-gamma and other cytokines on collagen synthesis in fetal rat bone cultures. Endocrinology 1987;120:2494-9.

24. Stashenko P, Dewhirst FE, Rooney ML, Desjardins LA, Heeley JD. Interleukin-1B is a potent inhibitor of bone formation in vitro. J Bone Miner Res 1987;2:559-65.

25. Tashjian AH, Voelkel EF, Lazzaro M, Goad D, Bosma T, Levine L. Tumor necrosis factor-alpha (cachectin) stimulates bone resorption in mouse calvaria via a prostaglandin mediated mechanism. Endocrinology 1987;120:2029-36.

26. Thomson BM, Saklatvala J, Chambers TJ. Osteoblasts mediate interleukin 1 stimulation of bone resorption by rat osteoclasts. J Exp Med 1986;164:104-12.

27. Miyaura C, Kusano K, Masuzawa T, et al. Endogenous bone-resorbing 
factors in estrogen deficiency: cooperative effects of IL-1 and IL-6. J Bone Miner Res 1995;10:1365-73.

28. Farman J, Effmann EL, Grnja V. Crohn's disease and periosteal new bone formation. Gastroenterology 1971;61:513-22.

29. Neale G, Kelsall AR, Doyle FH. Crohn's disease and diffuse symmetrical periostitis. Gut 1968;9:383-7.

30. Bookman AAM, Gould MI, Barrowman JA, Chittal SM. Periosteal new bone formation and disseminated granulomatosis in a patient with Crohn's disease. Am J Med 1988;84:330-4.

31. Lindstrom C, Wramsby H, Ostberg G. Granulomatous arthritis in Crohn's disease. Gut 1972;13:257-9.

32. Nugent FW, Glaser D, Herlihy-Fernandez L. Crohn's colitis associated with granulomatous bone disease. N Engl J Med 1976;294:262-3.

33. Greenberg GR, Feagan BG, Martin F, et al. Oral budesonide for active Crohn's disease. N Engl J Med 1994;331:836-41.

34. Greenberg GR, Feagan BG, Martin F, et al. Oral budesonide as maintenance treatment for Crohn's disease: a placebo-controlled, dose-ranging study. Gastroenterology 1996;110:45-51.

35. Brattsand R. Overview of newer glucocorticoid preparations for inflammatory bowel disease. Can J Gastroenterol 1990;4:407-14.

36. Ostergaard Thomsen O. Safety overview of budesonide in inflammatory bowel diseases. Res Clin Forums 1996;18:91-100.

37. Morgan A, Yates AK. Diagnosis of acute osteomyelitis of the pelvis. Postgrad Med J 1966;42:74-8.

38. Goldstein MJ, Nasr K, Singer HC, Anderson JGD, Kirsner JB. Osteomyelitis complicating regional enteritis. Gut 1969;10:264-6.

39. London D, Fitton JM. Acute septic arthritis complicating Crohn's disease. Br J Surg 1970;57:536-8.

40. Meltzer SS. Granulomatous enterocolitis complicated by osteomyelitis. Am J Gastroenterol 1973;59:77-80.

41. Ghahremani GG. Osteomyelitis of the ilium in patients with Crohn's disease. Am J Roentgenol 1973;118:364-70.

42. Pattison CP, Moeller DD. Escherichia coli osteomyelitis after sepsis in regional enteritis: report of a case. Am J Gastroenterol 1982;77:45-7.

43. Simpson MB. Pelvic-femoral osteomyelitis complicating Crohn's disease. Am J Gastroenterol 1984;79:379-81.

44. Schwartz CM, Demos TC, Wehner JM. Osteomyelitis of the sacrum as the initial manifestation of Crohn's disease. Clin Orthop 1987;222:181-5.

45. Gold RH, Hawkins RA, Katz OD. Bacterial osteomyelitis: findings on plain radiography, CT, MR and scintigraphy. Am J Roentgenol 1991;157:365-70.

46. Fishman EK, Wolf EJ, Jones B, Bayless TM, Siegelmann SS. CT evaluation of Crohn's disease: effect on patient management. Am J Roentegenol 1987;148:537-40.

47. Miller LK, Miller JW. Pelvic osteomyelitis complicating Crohn's disease: diagnosis by computed tomography. Am J Gastroenterol 1987;82:371-3.

48. Meyers SP, Wiener SN. Diagnosis of hematogenous pyogenic vertebral osteomyelitis by magnetic resonance imaging. Arch Intern Med 1991;151:683-7.

49. Aitken RJ, Wright JP, Bok A, Elliot MS. Crohn's disease precipitating a spinal extradural abscess and paraplegia. Br J Surg 1986;73:1004-5.

50. Sacher M, Gopfrich H, Hochberger O. Crohn's disease penetrating into the spinal canal. Acta Pediatr Scand 1989;78:647-9.

51. Hershkowitz S, Link R, Ravden M, Lipow K. Spinal empyema in Crohn's disease. J Clin Gastroenterol 1990;12:67-9.

52. Dich VQ, Nelson YD, Haltalin KC. Osteomyelitis in infants and children. Am J Dis Child 1975;129:1273-8.

53. Kwan WCP, Freeman HJ. Pelvic osteomyelitis complicating Crohn's disease. Can J Gastroenterol 1993;7:293-6.

54. Potasman I, Even L, Banai M, Cohen E, Angel D, Jaffe M. Brucellosis: an unusual diagnosis for a seronegative patient with abscesses, osteomyelitis, and ulcerative colitis. Review Inf Dis 1991;13:1039-41.

55. Mankin HJ. Nontraumatic necrosis of bone (osteonecrosis). N Engl J Med 1992;326:1473-9.

56. Brom B, Bank S, Marks IN, Cobb JJ. Periostitis, aseptic necrosis, and arthritis occurring in a patient with Crohn's disease. Gastroenterology 1971;60:1106-9.

57. Shapiro SC, Rothskin FC, Newman AJ, Fletcher B, Halpin TC Jr. Multifocal osteonecrosis in adolescents with Crohn's disease: a complication of therapy? J Pediatr Gastroenterol Nutr 1985;4:502-6.
58. Vakil N, Sparberg M. Steroid-related osteonecrosis in inflammatory bowel disease. Gastroenterology 1989;96:62-7.

59. Culp RW, Schaffer JL, Osterman AL, Bora FW. Kienbock's disease in a patient with Crohn's enteritis treated with corticosteroids. J Hand Surg [Am] 1989;14A:294-6.

60. Madsen PV, Andersen G. Multifocal osteonecrosis related to steroid treatment in a patient with ulcerative colitis. Gut 1994;35:132-4.

61. Freeman HJ, Kwan WCP. Non-corticosteroid-associated osteonecrosis of the femoral heads in two patients with inflammatory bowel disease. N Engl J Med 1993;329:1314-6.

62. Kawai K, Maruno H, Watanabe Y, Hirohata K. Fat necrosis of osteocytes as a causative factor in idiopathic osteonecrosis in heritable hyperlipemic rabbits. Clin Orthop 1980;153:273-82.

63. Periera GR, Fox WW, Stanley CA, Baker L, Schwartz JG. Decreased oxygenation and hyperlipemia during intravenous fat infusions in premature infants. Pediatrics 1980;66:26-30.

64. Cruess RL. Steroid-induced osteonecrosis: a review. Can J Surg 1981;24:567-71.

65. Pietroande V, Mastromarino R. Osteopatia da prolungata traitamento corisonico. Orthop e Traumatol 1957;25:791-810.

66. Heimann WG, Freiberger RH. Avascular necrosis of the femoral and humeral heads after high dosage corticosteroid therapy. N Engl J Med 1960;263:672-5.

67. Patterson RJ, Bickel WH, Dahlin DC. Idiopathic avascular necrosis of the head of the femur. J Bone Joint Surg 1964;46:267-82.

68. Merle D'Aubigne R, Postel M, Mazabraud A, Massias P, Guerguen J. Idiopathic necrosis of the femoral head in adults. J Bone Joint Surg 1965:47:612-33.

69. Fisher DE, Bickel WH. Corticosteroid-induced avascular necrosis. A clinical study of seventy-seven patients. J Bone Joint Surg 1971;53:859-73.

70. Huberman ET, Cristofaro RI. Avascular necrosis of bone as a complication of renal transplantation. Semin Arthritis Rheum 1976;6:189-206.

71. Elmstadt E. Incidence of skeletal complications in renal graft recipients. Effects of changes in pharmacotherapy. Acta Orthop Scand 1982;53:853-6.

72. Zizic TM, Hungerford DS, Stevens MB. Ischemic bone necrosis in systemic lupus erythematosus. The early diagnosis of ischemic necrosis of bone. Medicine (Baltimore) 1980;59:134-42.

73. Bergstein JM, Wiens P, Fish AJ. Avascular necrosis of bone in systemic lupus erythematosus. J Pediatr 1974;85:31-5.

74. Klippel JH, Gerber LH, Pollak L, Decker JL. Avascular necrosis in systemic lupus erythematosus. Am J Med 1979;67:83-7.

75. Smith EF, Sweet DE, Brunner CM. Avascular necrosis in systemic lupus erythematosus. An apparent predilection for young patients. Ann Rheum Dis 1976;35:227-32.

76. Timothy AR, Tucker AK, Park WM, Cannell LB. Osteonecrosis in Hodgkin's disease. Br J Radiol 1978;51:328-32.

77. Prosnitz LR, Lawson JP, Friedlaender GE. Avascular necrosis of bone in Hodgkin's disease patients treated with combined modality therapy. Cancer 1981;47:2793-7.

78. Englel IA, Straus DJ, Lacher M. Osteonecrosis in patients with malignant lymphoma: a review of twenty-five cases. Cancer 1981;48:1245-50.

79. Thorne JC, Evans WK, Alison RE, Fournasier V. Avascular necrosis of bone complicating treatment of malignant lymphoma. Am J Med 1981;71:571-8.

80. Jaffe NL, Ebstein M, Heyman W. The effect of cortisone in femoral and humeral heads in rabbits. An experimental study. Clin Orthop 1972;82:221.

81. McCluskey J, Gutteridge DH. Avascular necrosis after high doses of dexamethasone during neurosurgery. BMJ 1982;284:333-4.

82. Fast A, Alon M, Weiss S, Zer-Aviv FR. Avascular necrosis of bone following short-term dexamethasone therapy for brain edema. J Neurosurg 1984;61:983-5.

83. Felson DT, Anderson JJ. Across-study evaluation of association between steroid dose and bolus steroids and avascular necrosis of bone. Lancet 1987;i:902-5.

84. Zizic TM, Marcoux C, Hungerford DS, Dansereau J-V, Stevens MB. Corticosteroid therapy associated with ischemic necrosis of bone in systemic lupus erythematosus. Am J Med 1985;79:596-604.

85. Kenzora JE, Glimcher MJ. The role of renal bone disease in the production of osteonecrosis. Orthopedics 1981;4:305-13. 


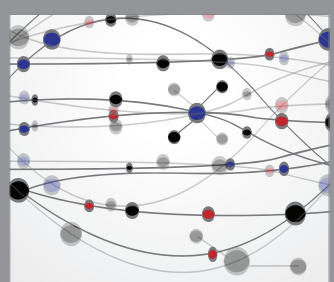

The Scientific World Journal
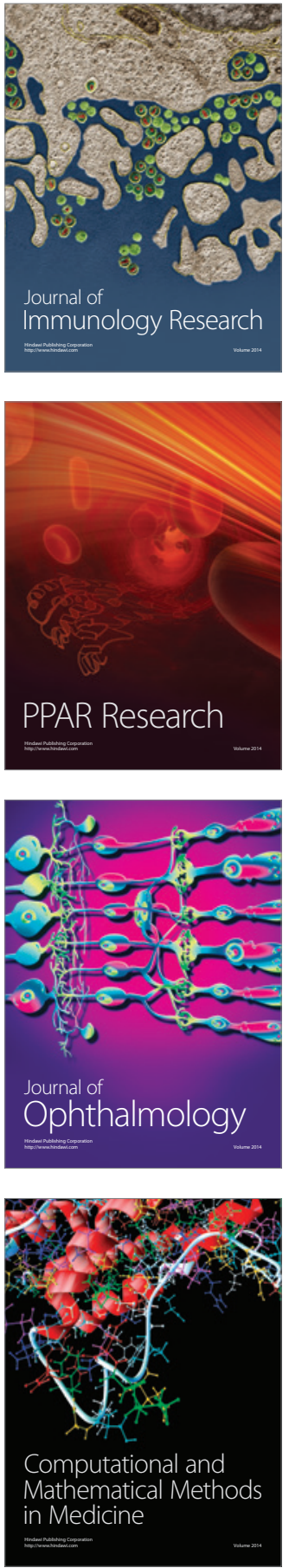

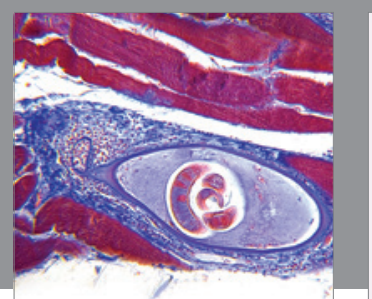

Gastroenterology Research and Practice

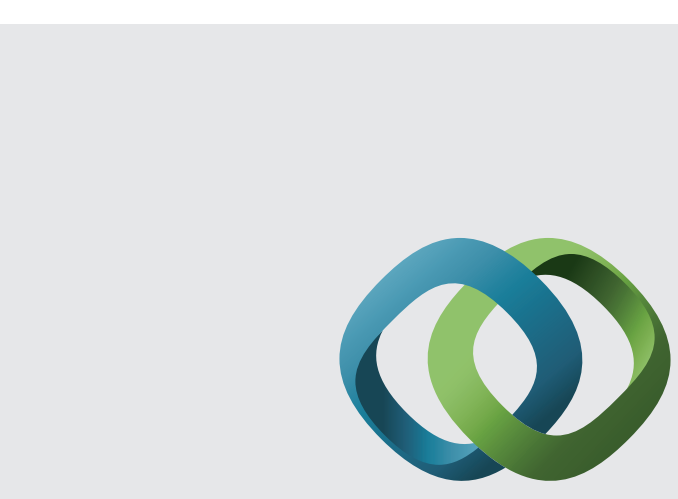

\section{Hindawi}

Submit your manuscripts at

http://www.hindawi.com
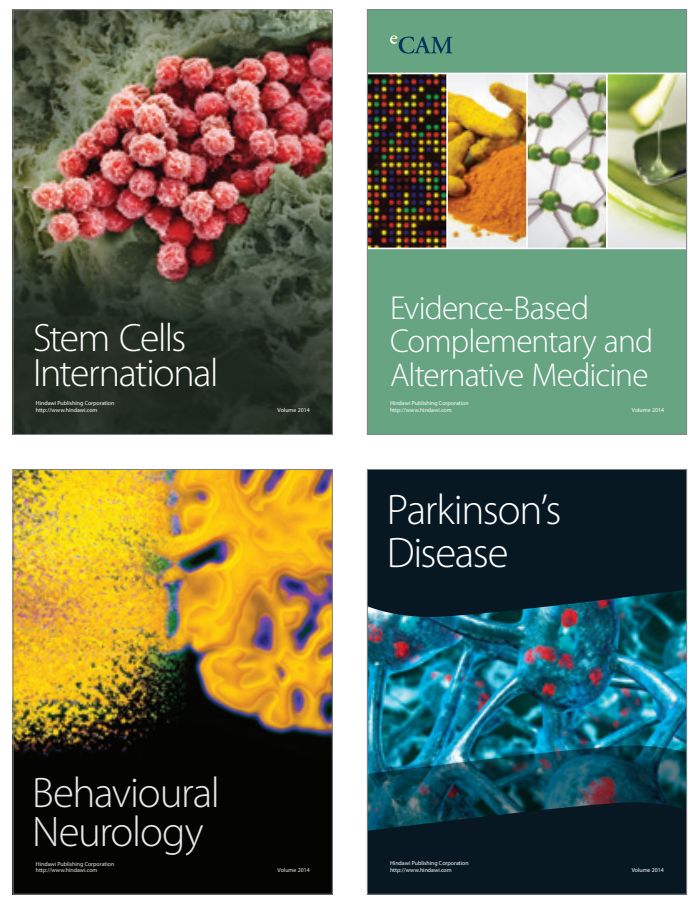
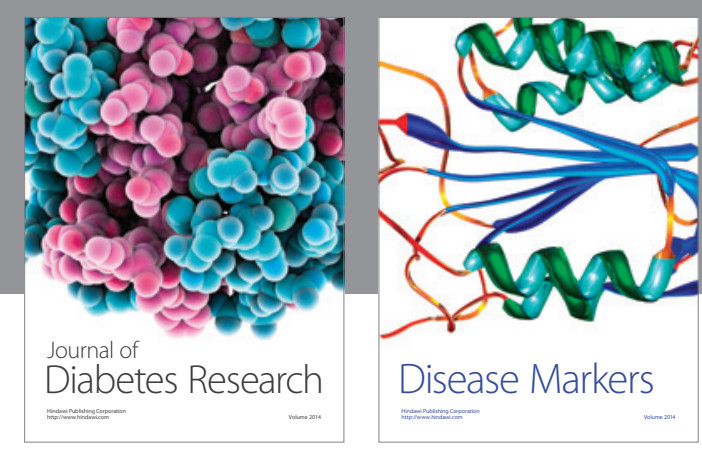

Disease Markers
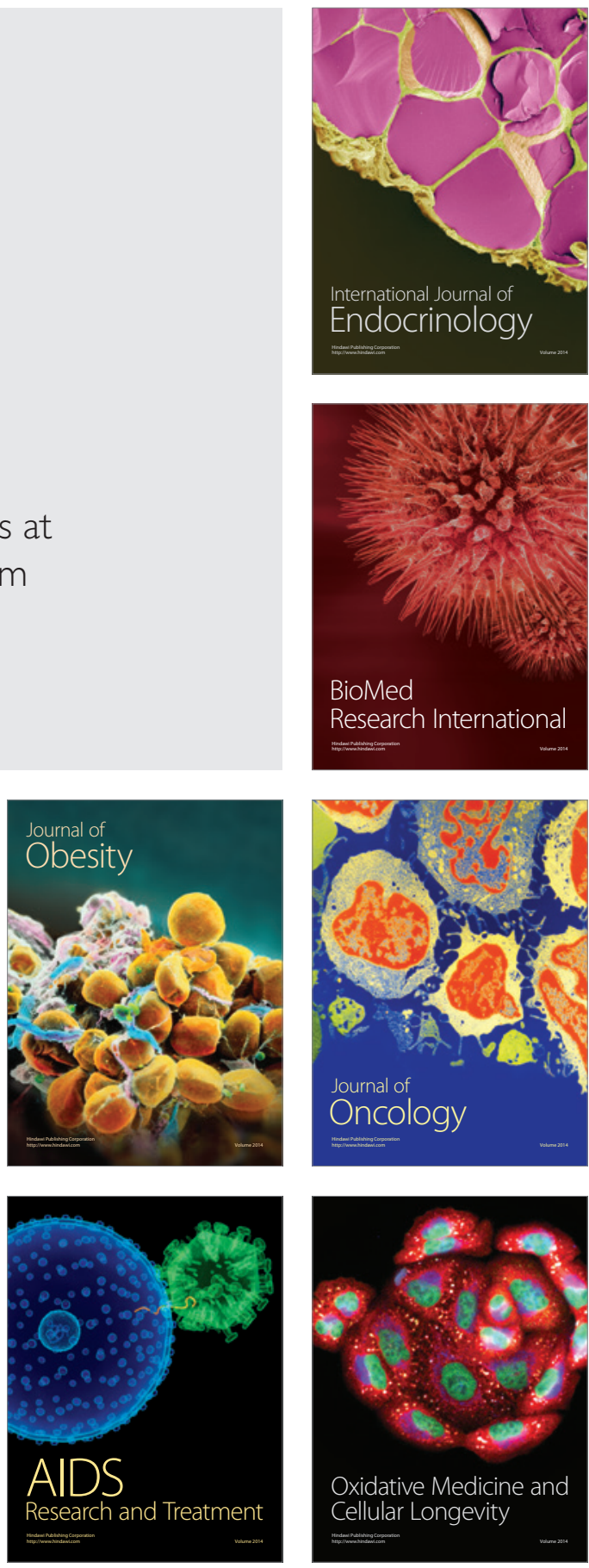